\title{
Automatic Sieve-Shaker for Determining Soil Aggregate Stability and Dimensional Distribution Using a Vertical Oscillation System
}

\author{
Rosario Dell'Aquila* \\ ISAFOM - CNR, Istituto per i Sistemi Agricoli e Forestali del Mediterraneo. \\ Consiglio Nazionale delle Ricerche \\ Via Patacca 85, 80056 Ercolano (NA), Italy
}

Received: 5 January 2007. Accepted: 10 October 2007.

\begin{abstract}
The soil aggregate stability is determined generally by sifting the soil samples in water using a sieve-shaker (wet sieving). The Author has developed an original model of automatic sieve-shaker using a vertical oscillation system to the aim of an its possible use to determine the soil aggregate stability and dimensional distribution. The purpose of this note is to describe the construction and performance of the prototype currently used in the Laboratory for the Soil Structure Study of the ISAFOM - CNR.

The proposed sieve-shaker, with the introduction of some innovations (protected by Italy Patent 0001332102), realizes the submersion and levelling of the soil samples using a lifter to support the containers with the water. With 6 workplaces it allows to process simultaneously up to 6 soil samples according to different test cycles. By means of the control panel it is possible to set up various determinations with the stroke of $3 \mathrm{~cm}$ and the oscillation frequency from 4 up to 80 oscillations per minute. The performance of the proposed sieve-shaker was verified with a technical test to verify the performance of the 6 workplaces to oscillation speed increasing up to 60 oscillations per minute and an agronomic test.

The results have been submitted to analysis of variance considering the plots of the field from which have been taken the samples for repetitions and the six workplaces of the proposed sieve-shaker for experimental theses. The differences between the various workplaces have not been significant. This demonstrates that the behavior of the various workplaces is uniform. The dispersion in water at constant shaking time and increasing oscillation speed has evidenced a very significant inverse relation between the index of aggregate stability in water (IASW) and number of oscillations per minute. This result demonstrates a constant performance of the proposed sieve-shaker to varying of the oscillation speed. The agnonomic test has demonstrated that the various workplaces of the proposed sieve-shaker do not present a significant difference of the performance and neither interactions with the treatments.

The proposed automatic sieve-shaker presents the advantage to be used both for the routine measures, with reference to ISO/TC 190/SC 5/WG 8 method, and for the research specific purposes by varying the oscillation frequency and shaking time.
\end{abstract}

Key-words: sieve-shaker, soil, aggregate, stability, dimensional distribution.

\section{Introduction}

The soil aggregate stability is determined generally by sifting the soil samples in water using a sieve-shaker (wet sieving) and the process of dispersion in water of the particles is important in the soil aggregate disaggregation (Pagliai et al., 1997). Therefore the submersion operation of more soil samples must be contemporary, rapid and undisturbed to obtain accurate mea- sures. The Author has developed an original model of automatic sieve-shaker using a vertical oscillation system to the aim of an its possible use to determine the soil aggregate stability and dimensional distribution.

The proposed sieve-shaker realizes the submersion and levelling of the soil samples using a lifter to support the containers with the water. With 6 workplaces it allows to process simultaneously up to 6 soil samples according to 


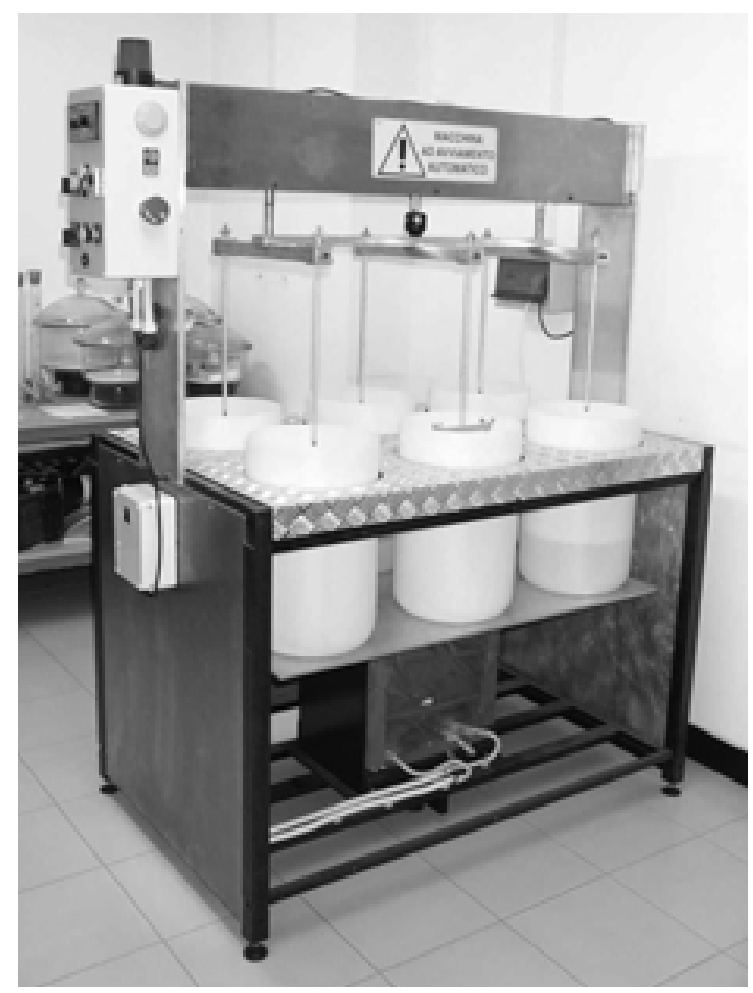

Figure 1 . The prototype of the proposed sieve-shaker.

different test cycles. Some innovations (protected by Italy Patent 0001332102 ), characterize the design of the proposed sieve-shaker with a considerable functionality for the laboratory automation. That confers greater accuracy to the measures and increases the productivity and operating safety. The prototype (Fig. 1) is used currently in the Laboratory for the Soil Structure Study of the ISAFOM - CNR both for routine measures, with reference to ISO/TC 190/SC 5/WG 8 method and for the research specific purposes by varying the oscillation frequency and shaking time.

\section{Materials and methods}

The components of the proposed sieve-shaker are represented in Figure 2. The mechanical lifter (1) is mounted in the structure (2). The mobile Table (3) supports the containers (4) with the water in the predefined position for the corrected levelling of the sieves (5) through the holes of the fixed top (6). The switch (7) is used for the direct mode control of the lifter. The proximity switches (8) and (9) restrict the ele-

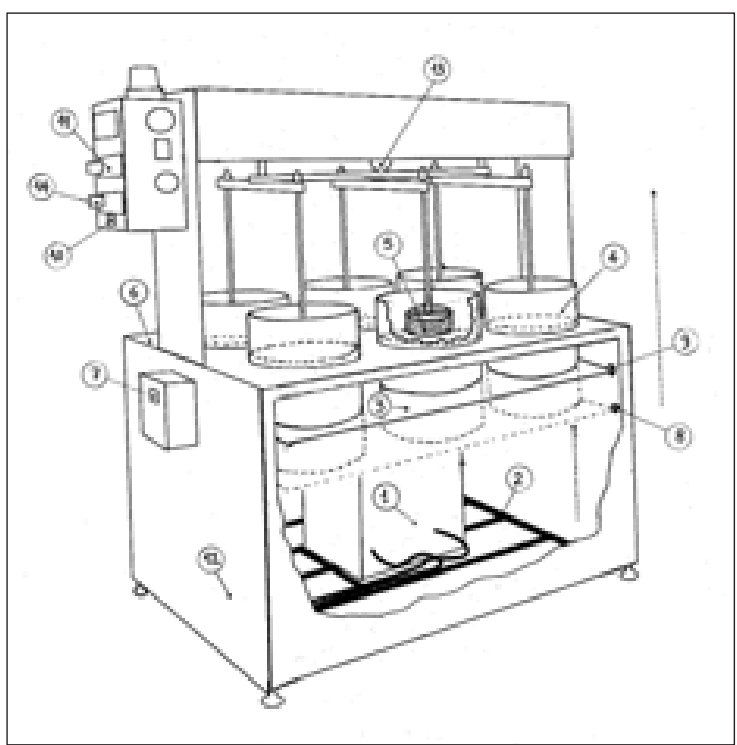

Figure 2. The components of the proposed sieve-shaker.

vating stroke to maximum $295 \mathrm{~mm}$. Other devices are the automatic/direct control (10) and the regulating device activating or deactivating the sifting at set times (11).

Four protections (12) close the lifter compartment and allow the rapid access to simplify the maintenance operations. Six sets of normalized sieves (inox steel 18/8 and diameters of 10 or $20 \mathrm{~cm}$, Giuliani Tecnologie) are subject, by means of the chassis (13), an electric motor asynchronous single-phase 2-poles (2800 rpm), a coaxial geared speed reducer with gear ratio 34.6 and a crank mechanism to vertical oscillation with the stroke of $3 \mathrm{~cm}$ and the adjustable oscillation frequency from 4 up to 80 oscillations per minute. The mechanical power is $140 \mathrm{~W}$ with rated torque of $13.8 \mathrm{Nm}$. The electric motor (Model PAR240M3, MiniMotor) is totally enclosed with external ventilation and supplied by electronic speed variator (Model RM220E, MiniMotor) from 0 to $230 \mathrm{~V}$ A.C. $/ 50 \mathrm{~Hz}$. The control panel (14) allows to set up various test cycles. The test cycles are electronically well-timed by the operator on display with memory of the set configuration and functions. The speed variation is obtained, with digital indication, by varying the power supply voltage to the motor at the right moment by means of a speed setting potentiometer on the panel. Moreover four incorporated trimmers are used for regulating the acceleration and deceleration ramp, the response 
time and maximum speed. A tachometer retroaction control allows maintaining a constant rotation speed of the motor in line with the variation of the load applied. A mobile table in aluminium alloy by means of a mechanical lifter (Model Tablolift, HÄFELE) supports and lifts up the HD polyethylene containers of the water up to $80 \mathrm{~kg}$ weight. The installation data are $1.48 \mathrm{~m}$ in frontal width, $82 \mathrm{~cm}$ in depth and 1.80 $\mathrm{m}$ in height. The total weight, with empty containers, is $350 \mathrm{~kg}$. The electric power required is $500 \mathrm{~W}$. The performance of the proposed sieveshaker was verified with a technical test to verify the performance of the 6 workplaces to oscillation speed increasing up to 60 oscillations per minute and an agronomic test.

\section{Results and discussion}

\subsection{Technical test}

It has been said previously that the proposed sieve-shaker has 6 workplaces to execute up to 6 determinations at same time. Therefore it has been verified the behavior of the various workplaces. To such aim, from 7 plots of the field in the Volturno Valley at Vitulazio (CE) they have been taken as many soil samples from the layer at depth 0-20 cm that subsequently have been dried at the air, disaggregated and therefore sifted until obtain 7 samples of aggregates between 1 and $2 \mathrm{~mm}$ in diameter. They have been numbered the sieves from 1 to 6 and has been assigned a number from 1 to 6 at every workplace, so as to coincide the workplace 1 with sieve 1 and so on. From each of the 7 samples of aggregates has been obtained 6 sub-samples of 30 $\mathrm{g}$ that, numbered from 1 to 6 , has been assigned to the corresponding sieves $(10 \mathrm{~cm}$ in diameter and a $0.2 \mathrm{~mm}$ mesh). Then it is determined the index of aggregate stability in water (IASW) according to the only one determination method (duration 30 minutes) with depuration from the sand and vertical oscillation (30 oscillations per minute with the stroke of $3 \mathrm{~cm}$ ) without prewetting soil samples (Pagliai et al., 1997). The results have been submitted to analysis of variance considering the plots of the field from which have been taken the samples for repetitions and the 6 workplaces for experimental theses. The differences between the workplaces have not been significant (Tab. 1). This demon-
Table 1. Relations between the index of aggregate stability in water (IASW) of the various workplaces.

\begin{tabular}{lcccccc}
\hline Workplace & $1^{\circ}$ & $2^{\circ}$ & $3^{\circ}$ & $4^{\circ}$ & $5^{\circ}$ & $6^{\circ}$ \\
\hline IASW (\%) & 68.9 & 68.7 & 66.8 & 66.4 & 69.9 & 67.2 \\
\hline
\end{tabular}

strates that the behavior of the various workplaces of the proposed sieve-shaker is uniform. An other possibility of the proposed sieve-shaker is to vary the oscillation speed of the sieves. It is important that the error of speed regulation is minimal and independent from the same oscillation speed. For this it has been verified the performance of the proposed sieve-shaker to oscillation speeds increasing up to 60 oscillations per minute. From two plots of the field in the Volturno Valley at Vitulazio (CE) have been taken two soil samples from the layer at depth 0-20 cm. The soil samples have been dried at the air, disaggregated and therefore sifted until obtain 2 samples of aggregates between 1 and $2 \mathrm{~mm}$ in diameter. From each sample have been obtained 4 groups of 6 sub-samples that have been submitted for 30 minutes to dispersion in water according to the above mentioned method (Pagliai et al., 1997) with $30 \mathrm{~g}$ of aggregates for each sieve at the speeds of 15,30 , 45 and 60 oscillations per minute.

In this way for every oscillation speed have been had 12 observations. The dispersion in water at constant time (30 minutes) with increasing oscillation speed $(15,30,45$ and 60 oscillations per minute) has evidenced (Fig. 3) a very significant inverse relation between the index of aggregate stability in water (IASW) and num-

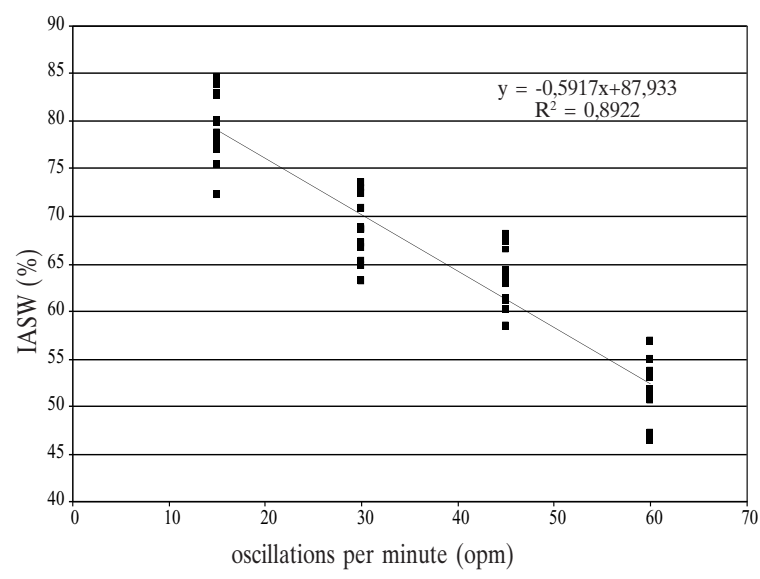

Figure 3. Relationship between IASW and number of oscillations per minute at constant time (30 minutes). 
Table 2. Soil chemical and physical traits of the Vitulazio experimental field, layers $0-0.4 ; 0.4-1.10 \mathrm{~m}$, identified as 20 and $75 \mathrm{~cm}$ soil depth.

\begin{tabular}{lccc}
\hline Parameters & Unit & \multicolumn{2}{c}{ Soil depths cm } \\
& & 20 & 75 \\
\hline Coarse sand & $\%$ & 3.2 & 5.6 \\
Fine sand & $\%$ & 20.8 & 26.8 \\
Silt & $\%$ & 36.34 & 30.4 \\
Clay & $\%$ & 39.6 & 37.2 \\
Organic Matter & $\%$ & 1.29 & 0.79 \\
CEC & cmol $(+) \mathrm{kg}^{-1}$ & 27.48 & 28.22 \\
$\mathrm{Ca}^{++}$ & $\mathrm{cmol}(+) \mathrm{kg}^{-1}$ & 25.34 & 23.05 \\
$\mathrm{Mg}^{++}$ & $\mathrm{cmol}(+) \mathrm{kg}^{-1}$ & 1.37 & 4.3 \\
$\mathrm{~K}^{+}$ & $\mathrm{cmol}(+) \mathrm{kg}^{-1}$ & 0.50 & 0.115 \\
$\mathrm{Na}^{+}$ & $\mathrm{cmol}(+) \mathrm{kg}^{-1}$ & 0.26 & 0.50 \\
ESP & $\%$ & 0.94 & 1.77 \\
Total Carbonates & $\%$ & 2.94 & 2.50 \\
pH in water & & 7.72 & 8.2 \\
ECe & dS m ${ }^{-1}$ & 0.89 & 0.92 \\
Field capacity & & & \\
(1500 kPa) & $\%$ vol. & 39.55 & 38.00 \\
Wilting point & & & \\
(33 kPa) & $\%$ vol. & 21.97 & 24.00 \\
\hline
\end{tabular}

Field capacity and wilting point were determined using the Richards apparatus.

ber of oscillations per minute. This result demonstrates a constant performance of the proposed sieve-shaker to varying of the oscillation speed.

\subsection{Agronomic test}

About the soil aggregate stability in relation to the salinity level after irrigation with saline water. In the year 1995 at the CNR-ISAFOM experimental farm, located in the Volturno Valley at $25 \mathrm{~m}$ a.s.l., $14^{\circ} 12^{\prime}$ long. $\mathrm{E}$ and $41^{\circ} 07^{\prime} \mathrm{N}$ in $\mathrm{Vi}$ tulazio (CE), has been performed an irrigation experiment with saline water at different concentration on the clay-silty soil (the characteristics are reported in Tab. 2). The spatial distribution at randomized block of the experimen- tal plots (Tab. 3) remained the same during the years of experimentation in order to assess the effects of salt accumulation. Therefore, the randomization has been only executed to the beginning of the experience. During the years of experimentation approximately $66 \%$ of the annual rainfall fell in the October-March period. The rainfall $(540 \mathrm{~mm}$ against the annual mean of $814 \mathrm{~mm}$ from 1976 to 2001) has been supposed sufficient to washing the salt introduced with the irrigation in the layers explored by the roots. Therefore it is preferred to neglect the leaching. All the treatments (Tedeschi and Dell'Aquila, 2005) are influenced by the salt quantity delivered, which depends on the irrigation regime and on the saline water concentration. In this note are reported the effects on the aggregate stability observed after 7 years of irrigation with saline water at $0.5 \%$ and $1 \%$ of Na$\mathrm{Cl}\left(\mathrm{ECw} \cong 10\right.$ and $15 \mathrm{dS} \mathrm{m}^{-1}$ respectively) in comparison to well water $\left(\mathrm{ECW} \cong 1 \mathrm{dS} \mathrm{m}^{-1}\right)$. For this purpose, during spring time of the year 2002 from 4 repetitions of the treatments $\mathrm{I}_{0}, \mathrm{I}_{0.5}$ and $\mathrm{I}_{1}$ they have been obtained 12 soil samples from the layer at depth $0-0.20 \mathrm{~m}$ that have been dried at the air, disaggregated and therefore sifted until obtain aggregate samples between 1 and 2 $\mathrm{mm}$ in diameter.

On such samples it has been determined the ECe and the ESP according to official methods (MiPAF, 2000). The conductivity in saturated paste has been determined by transforming the $\mathrm{EC}_{1: 2.5}$ in $\mathrm{ECe}$ by means of the relation obtained experimentally for the soils of Vitulazio (Tedeschi et al., 2002). Also the index of the aggregate stability in water (IASW) has been determined only for the layer at depth $0-0.20 \mathrm{~m}$. For the IASW each above mentioned samples has been subdivided in 6 sub-samples of $30 \mathrm{~g}$

Table 3. Description of the irrigation treatments.

\begin{tabular}{|c|c|c|c|}
\hline Treatments & Description & $\begin{array}{c}\text { Irrigation volume } \\
0-0.4 \text { m layer } \\
\% \text { of ETM }\end{array}$ & $\begin{array}{c}\text { Quantity of } \mathrm{NaCl} \\
\text { applied } \\
\left(\mathrm{t} \mathrm{ha}^{-1} \text { year }^{-1}\right)\end{array}$ \\
\hline $\mathrm{I}_{0}$ & Normal water $\left(\mathrm{ECw} \cong 1 \mathrm{dS} \mathrm{m}^{-1}\right)$ & 100 & 0.09 \\
\hline $\mathrm{I}_{0.25}$ & Normal water with $0.25 \%$ of $\mathrm{NaCl}\left(\mathrm{ECw} \cong 5 \mathrm{dS} \mathrm{m}^{-1}\right)$ & 100 & 6.6 \\
\hline $\mathrm{I}_{05}$ & Normal water with $0.5 \%$ of $\mathrm{NaCl}\left(\mathrm{ECw} \cong 10 \mathrm{dS} \mathrm{m}^{-1}\right)$ & 100 & 12.3 \\
\hline $\mathrm{I}_{1}$ & Normal water with $1 \%$ of $\mathrm{NaCl}\left(\mathrm{ECW} \cong 15 \mathrm{dS} \mathrm{m}^{-1}\right)$ & 100 & 22.3 \\
\hline $\mathrm{S}_{0}$ & Normal water $\left(\mathrm{ECw} \cong 1 \mathrm{dS} \mathrm{\textrm {m } ^ { - 1 } )}\right.$ & 40 & 0.03 \\
\hline $\mathrm{S}_{0.25}$ & Water as $\mathrm{I}_{0.25}\left(\mathrm{ECw} \cong 5 \mathrm{dS} \mathrm{m}^{-1}\right)$ & 40 & 2.5 \\
\hline $\mathrm{S}_{0.5}$ & Water as $\mathrm{I}_{0.5}\left(\mathrm{ECW} \cong 10 \mathrm{dS} \mathrm{m}^{-1}\right)$ & 40 & 4.7 \\
\hline
\end{tabular}




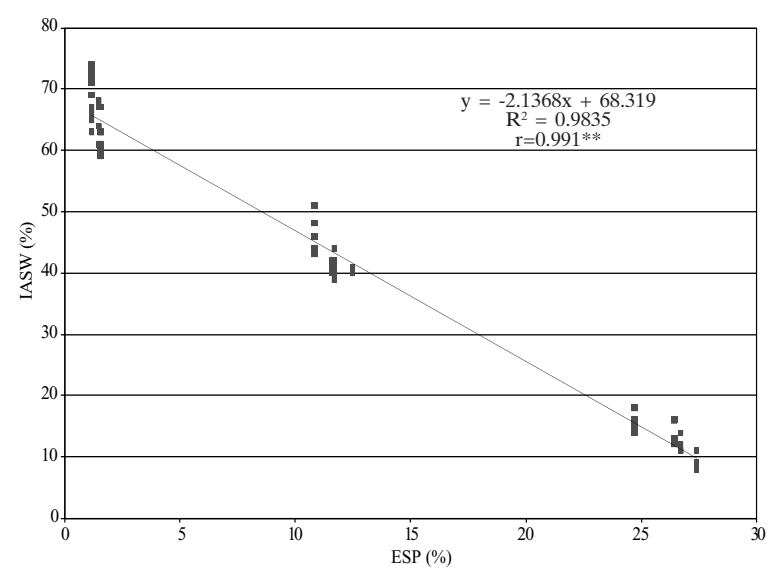

Figure 4. Relationship between IASW and ESP (**indicate the level of significance $\mathrm{P} \leq 0.01$ ).

assigned to the workplaces of the proposed sieve-shaker and analyzed according to the only one determination method with depuration from the sand and vertical oscillation (Pagliai et al., 1997). For every treatment have been executed 24 determinations for a total of 72 (6 corresponding sub-samples to the workplaces of the proposed sieve-shaker multiplied by 4 repetitions in field and by 3 irrigated treatments). The analysis of variance, executed after the angular transformation of the index values of aggregate stability in water (Tab. 4), has evidenced a very significant difference between the treatments $\mathrm{I}_{0}, \mathrm{I}_{0.5}$ and $\mathrm{I}_{1}$ (the IASW has been respectively 66.1, 42.3 and 12.7). The various workplaces of the proposed sieve-shaker do not present a significant difference of the performance and neither interactions with the treatments. In default of a sieve-shaker using alternated spin system it has not been possible to confront the two sieve-shakers (that one working with vertical oscillation and that one with alternated spin).

Therefore it is not possible to understand if

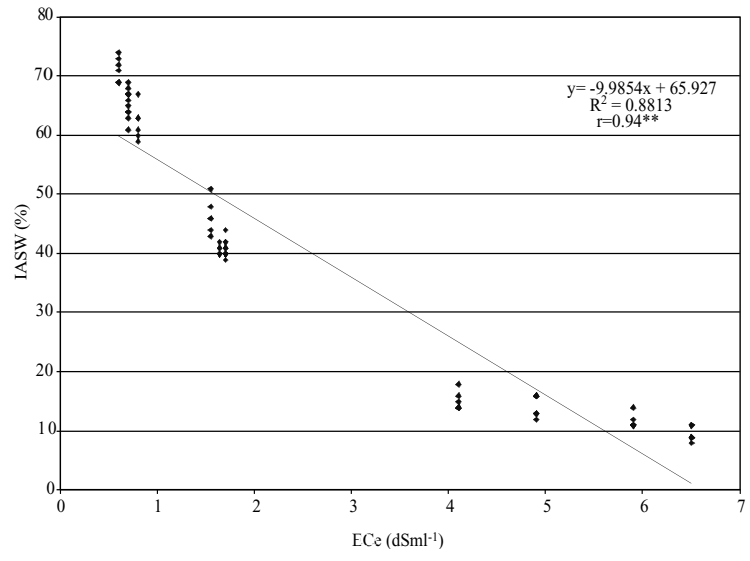

Figure 5. Relationship between IASW and ECe (**indicate the level of significance $\mathrm{P} \leq 0.01$ ).

the difference between the IASW observed after 3 and 7 years $(77.0,30.5$ and 16.2 respectively for $I_{0}, I_{0.5}$ and $I_{1}$ after 3 years and 66.1, 42.3 and 12.7 respectively for $\mathrm{I}_{0}, \mathrm{I}_{0.5}$ and $\mathrm{I}_{1}$ after 7 years) is due at the adopted methodology or at the experimental variables. In any case it goes remembered that "the measures of aggregates stability have only comparative value for a data method applied in standard mode and in the same experimental conditions" (Pagliai et al., 1997). In spite of all is interesting to observe that the measures repeated after 7 years with other methodology have confirmed a very significant inverse relation, already evidenced after 3 years of irrigation with saline water (Tedeschi, 1999), between the IASW and the ESP (Fig. 4) and between the IASW and the ECe (Fig. 5).

\section{Acknowledgements}

The suggestions of Prof. Pasquale Tedeschi and Dr. Anna Tedeschi are gratefully acknowledged.

Table 4. Relations between the IASW of the treatments $I_{0}, I_{0.5}$ and $I_{1}$.

\begin{tabular}{|c|c|c|c|c|c|c|c|}
\hline \multirow[t]{2}{*}{ Treatments } & \multicolumn{6}{|c|}{ Workplaces } & \multirow[b]{2}{*}{$\mathrm{m}$} \\
\hline & $1^{\circ}$ & $2^{\circ}$ & $3^{\circ}$ & $4^{\circ}$ & $5^{\circ}$ & $6^{\circ}$ & \\
\hline $\mathrm{I}_{0}\left(\mathrm{ECW} \cong 1 \mathrm{dS} \mathrm{\textrm {m } ^ { - 1 }}\right)$ & 62.8 & 68.0 & 63.5 & 66.0 & 66.5 & 64.5 & $66.1^{* * * *}$ \\
\hline $\mathrm{I}_{0.5}\left(\mathrm{ECW} \cong 10 \mathrm{dS} \mathrm{m}^{-1}\right)$ & 42.8 & 42.5 & 42.3 & 42.0 & 42.0 & 42.3 & $42.3^{* * *}$ \\
\hline $\left.\mathrm{I}_{1}(\mathrm{ECW} \cong 15 \mathrm{dS} \mathrm{m})^{-1}\right)$ & 11.8 & 12.0 & 12.8 & 13.8 & 12.0 & 13.5 & $12.7^{* * * *}$ \\
\hline $\mathrm{m}$ & 40.8 & 40.8 & 39.5 & 40.6 & 40.2 & 40.1 & \\
\hline
\end{tabular}

*** level of significance $\mathrm{P} \geq 0.001$. 


\section{References}

MiPAF - Ministero per le Politiche agricole e forestali - Osservatorio nazionale pedologico e per la qualità del suolo, 2000. Metodi di Analisi Chimica del Suolo. Collana di metodi analitici per l'agricoltura diretta da Paolo Sequi, n. 1124.2. Franco Angeli, Milano.

Pagliai M., Torri D., Patruno A. 1997. Stabilità e distribuzione dimensionale degli aggregati. In: Metodi di Analisi Fisica del Suolo del MiPAF. Osservatorio nazionale podologico e per la qualità del suolo, V, 113. Franco Angeli, Milano.

Tedeschi A. 1999. Influence of soil sample conditioning in the evaluation of soil structure stability as affected by irrigation with saline water. Italian Journal of Agronomy, 3, 2:117-122.

Tedeschi A., Dell'Aquila R. 2005. Effects of irrigation with saline waters, at different concentrations, on soil physical and chemical characteristics. Agricultural Water Management, 77:308-322.

Tedeschi A., Soprano M., Calandrelli D., Martorella A., Balsamo A., Castiello G., Romano G., Romano C. 2002. Effetti a medio termine dell'irrigazione con acque saline su alcune caratteristiche chimico-fisiche del suolo. Atti del Convegno Inaugurazione ISAFOM, 24-25 settembre 2002, Portici (NA), Italy. 